\title{
Education scholarship in emergency medicine part 3: a "how-to" guide
}

\author{
Farhan Bhanji, MD, MSc(HPE)*; Adam Cheng, $\mathrm{MD}^{\dagger}$; Jason R. Frank, MD, MA(Ed) ${ }^{\ddagger}$; \\ Linda Snell, MD, MHPE*; Jonathan Sherbino, MD, MEd ${ }^{\S}$
}

\begin{abstract}
Successful emergency medicine (EM) education scholarship requires a systematic approach that includes searching the (grey) literature, mobilizing resources, adopting frameworks to focus the innovation, integrating a component of program evaluation, and disseminating the innovation via traditional and emerging avenues. This paper provides direction for EM teachers and educators looking to transform their education innovation into scholarship. Recommendations on producing EM education scholarship from the 2013 consensus conference of the Academic Section of the Canadian Association of Emergency Physicians are presented.
\end{abstract}

\section{RÉSUMÉ}

Pour qu'un programme de bourses d'études en éducation, applicables à la MU, soit couronné de succès, il faut adopter une approche systématique qui comprend la recherche dans la documentation (parallèle), la mobilisation des ressources, I'adoption de cadres ayant pour objet principal I'innovation, l'intégration d'un élément d'évaluation du programme, et la diffusion de l'innovation par des moyens classiques et nouveaux. L'article donne une orientation aux enseignants et aux éducateurs en MU désireux de voir leurs innovations en éducation se transformer en bourse d'études. Seront présentées les recommandations sur les bourses d'études en éducation, applicables à la $\mathrm{MU}$, issues de la conférence de consensus de 2013, tenue par la division Academic de l'Association canadienne des médecins d'urgence.

\section{Keywords: education scholarship, emergency medicine,} research process

The emergency department is increasingly recognized as an important learning environment, with the majority of current Canadian-trained physicians spending time learning in the clinical emergency environment. Unfortunately, the amount of emergency medicine (EM) education scholarship has not matched the tremendous output in EM teaching. When education innovations are locally developed, they are rarely shared, resulting in other EM programs spending untold hours redeveloping similar innovations. ${ }^{1}$

This paper provides a "how-to" guide to developing scholarly projects related to education innovations that many EM physicians may already be engaged in. Traditional research, the other subtype of education scholarship, falls beyond the scope of practice for most EM teachers and educators and is not discussed in this paper. Interested individuals are directed elsewhere for relevant resources. ${ }^{2}$ Building on the companion work of Sherbino and colleagues and Bandiera and colleagues in this issue of $C F E M,{ }^{3,4}$ this paper outlines key principles to transform an innovation into education scholarship. Finally, the related recommendations from the 2013 consensus conference of the Academic Section of the Canadian Association of Emergency Physicians (CAEP) are presented.

\section{WHY SHOULD THE EM COMMUNITY CARE ABOUT EDUCATION SCHOLARSHIP?}

Teaching at its best means not only transmitting knowledge, but transforming it and extending it as well. It keeps the flame of scholarship alive. ${ }^{5}$

Teaching is a core activity in academic EM. Done well, it can profoundly influence learners and become a

From the ${ }^{*}$ Centre for Medical Education, McGill University, Montreal, QC; †Department of Pediatrics, University of Calgary, Calgary, AB; $\neq D e p a r t m e n t$ of Emergency Medicine, University of Ottawa, Ottawa, ON; and §Division of Emergency Medicine, McMaster University, Hamilton, ON.

Correspondence to: Dr. Jonathan Sherbino, McMaster Clinic, Hamilton General Hospital, 237 Barton Street East, Hamilton, ON L8L 2X2; sherbino@ mcmaster.ca.

This article has been peer reviewed. 
domain of personal satisfaction for the teacher. When teaching moves beyond intuition and personal experience to incorporate best available evidence, it can be referred to as scholarly. Education scholarship extends beyond scholarly teaching and involves the development of an innovation that meets the criteria discussed in the companion paper. ${ }^{3}$ It allows an innovation to influence learners beyond the local learning environment. ${ }^{6}$ Through scholarship, we are able to promote and validate medical education as a core mission within academic institutions, ensuring its place alongside traditional academic activities such as clinical/bench research and clinical care.

Education scholarship can lead to personal satisfaction, recognition by peers, and, perhaps in the future, academic reward and promotion; it can improve education for learners and provide better care for patients. ${ }^{1}$ Building a community of education scholars has the potential to facilitate the dissemination of work, promote peer review and discussion, and provide opportunities for collaboration. ${ }^{7,8}$ It also fosters further innovation and scholarship among members of the EM community and can help promote the specialty of EM as a leader in medical education.

\section{TEACHING, SCHOLARLY TEACHING, AND EDUCATION SCHOLARSHIP: REVIEW OF THE LITERATURE}

\section{A senior resident approaches you to develop a pediatric resuscitation simulation module.}

The typical response from a busy EM clinician (and many educators) would be to brainstorm with the resident and develop a module to meet perceived learning needs. This ad hoc, intuitive approach is common in traditional teaching. Few teachers would take the time to review the published education literature to develop a robust module. This evidencebased approach equates to scholarly teaching. Fewer still would consciously plan to add to the medical education field by developing an evidence-based, innovative module and disseminating it for peer review. This is the standard required of education scholarship.

Too often our responses to education issues or questions are completely opposite to our evidencebased approach to clinical care-based on intuition and preconceived notions rather than scientific evidence or consensus-based best practice. Limits exist as to what busy teachers or educators can do. We are not advocating that every education project needs to incorporate the elements of education scholarship. However, teachers should consider implementing scholarly teaching as often as possible to maximize the effectiveness of their efforts and prevent an overreliance on intuition or personal teaching experience. Successful teachers should on some occasions share (and archive) their scholarly teaching innovation for peer review to transform it into scholarship.

\section{TO DO OR NOT TO DO IS THE QUESTION: IDENTIFY AND MOBILIZE RESOURCES}

\section{A senior resident wants to develop a pediatric resuscitation workshop for her junior colleagues. She would like to study the impact of the intervention as part of a medical education elective. She values your clinical and educational expertise and asks you to supervise her.}

Education scholarship has the power to affect learners beyond local institutions, so dissemination of information should be integral to the core goals of as many education innovations as possible. Careful planning at the beginning maximizes the possibility of success. Table 1 provides key steps. Scholars should assess their personal motivation and organizational resources to

Table 1. Key steps to enhance your education scholarship in EM

1. Determine if you have the time and motivation to transform your innovation into scholarship. It will not be feasible for every idea.

2. Partner with established scholars, particularly if you have limited experience. Look for partners inside and outside EM.

3. Incorporate the criteria for scholarship into your innovation at the beginning. Adding required elements at a later stage may not be possible or may limit the quality of the scholarship.

4. Review existing theories, principles, or best practices so that your innovation advances (rather than duplicates) the field.

5. Use peer review at multiple stages to refine and improve the quality of the innovation.

6. Build capacity by including junior colleagues in your projects. They may become the next generation of EM education scholars.

7. Incorporate an evaluation process so that you can determine the outcome of your innovation.

8. Discuss your innovation and evaluation process with your institutional review board (i.e., ethics) before you start.

9. Use a framework to guide the development of your innovation and focus your scholarship.

10. Improve your abilities as an education scholar by participating in a community of practice, including serving as a peer reviewer.

$\mathrm{EM}=$ emergency medicine 
complete a project before taking the first step. Without adequate time, commitment, and resources, a project is destined to fail.

Obtaining resources can be challenging. Research grants typically fund only education research, not innovation development. In-kind contributions may provide an alternative for necessary resources. Scholars should treat their education projects as a core activity, protecting time in a busy schedule. They should never work in isolation! Collaborating with experienced colleagues is critical, be they local (e.g., within the department, within the faculty of medicine, within the university) or external (e.g., across EM departments, with national education organizations).

Innovation must build on existing theories, principles, or best practices to be considered scholarly. This requires a search of the literature, including the grey literature (i.e., nonindexed resources available via Google Scholar). Getting help from information specialists (e.g., librarians) may be useful for those with limited experience in conducting systematic literature searches. Peer review before embarking on the scholarly project, both within and outside EM, can further determine if any supporting evidence has been omitted and, more importantly, whether the proposed innovation is worth pursuing. Ideally, a portion of this review should come from leaders in the field (e.g., conference reviewers, journal editors) who understand the issues specific to both EM and education.

Finally, scholars should be conscious of their role as mentors. Mentorship, although informal, carries considerable influence on the academic path of a junior colleague. Individuals early in their education career should be connected with experienced education scholars for career counselling. ${ }^{9}$

\section{"I'M ALL IN": USE EDUCATION FRAMEWORKS FOR GUIDANCE}

You agree to supervise your junior colleague. How do you decide where to focus?

Any activity related to the design, implementation, or evaluation of education innovations can be transformed into education scholarship. ${ }^{10}$ However, important additions to EM education are made through focusing the scholarly activity.

Kern and colleagues' six-step model provides a useful framework (designed for curriculum development) to guide the development of an innovation and focus the associated scholarship. ${ }^{11}$ The steps are as follows:

1. Problem identification and general needs assessment

2. Needs assessment

3. Development of goals and objectives

4. Instructional methods

5. Implementation

6. Evaluation and feedback

Alternate models of education design exist ${ }^{12}$ and could help guide the design of the invocation and the related scholarship. Frank's model proposes four categories of education scholarship: what to teach/assess, how to teach/assess, what works, and why it works. ${ }^{2}$

\section{DID IT WORK? INTEGRATE PROGRAM EVALUATION}

Evaluation is a critical, but often underdeveloped, step in innovation development. It is imperative to study the impact an innovation has had to determine if it is meeting its desired goals and to discover unanticipated outcomes. Employed early and consistently, evaluation can help determine the merit of the innovation. ${ }^{13}$ There is no single or best evaluation method that can be applied to all situations. Kirkpatrick's model ${ }^{14}$ has been widely adopted for its practicality and familiarity in the education community. Kirkpatrick outlines four levels of evaluation, moving hierarchically from the bottom level of learner reaction (i.e., How much does the learner like the innovation?). The second level is evaluation of learning. The third level evaluates the behaviour of the learner with respect to application of the innovation in practice (i.e., Does the learner apply the knowledge and act appropriately?). Finally, the top level evaluates the results of the innovation (i.e., What are the outcomes of the innovation beyond the impact on the learner?) For the pediatric resuscitation workshop described above, this level would evaluate improved survival for pediatric patients resulting from the workshop. Evidence at each successively higher level generally requires a more rigorous and complex analysis. Focusing on Kirkpatrick's top level is uncommon for most innovations ${ }^{13-16}$ and may not be necessary for smaller-scale local projects. ${ }^{17}$

\section{WHERE CAN YOU SHARE YOUR WORK? DISSEMINATE}

For an innovation to be considered scholarship, it must be disseminated publicly so that it is open for peer 
review and critique and, most importantly, so that it can improve education and patient care. Opportunities for dissemination of education scholarship in EM are growing, including conferences, journals, ${ }^{18}$ and Webbased portals. Changes in EM education can be rapid-what was innovative 3 years ago may be routine and not relevant for publication or presentation now. Examples of venues to present education scholarship are shown in Table 2.

\section{RECOMMENDATIONS}

In 2013, the Academic Section of the CAEP held a consensus conference on education scholarship. Through a process that included a review of the literature, expert thematic analysis, and iterative consensus agreement, the following recommendations were supported:

\section{PRODUCING EM EDUCATION SCHOLARSHIP}

1. The Academic Section should facilitate quality Canadian EM education scholarship.

- Action Item: The Academic Section should facilitate the creation of a community of practice to assist individuals in turning their education projects into scholarship.

- Action Item: The Academic Section should create an operations network to facilitate potential multi-centre EM education projects. Infrastructure barriers (e.g. need for a local investigator at each site, different ethics applications at each site etc.) should be addressed by this network.

- Action Item: The Academic Section should facilitate a national forum among education scholars and leaders to ensure that key EM education questions are expressed.

- Action Item: The CAEP research committee should make education scholarship (i.e. education innovation) projects eligible for research award funding using rigorous criteria that appropriately evaluate innovations. Education scholars

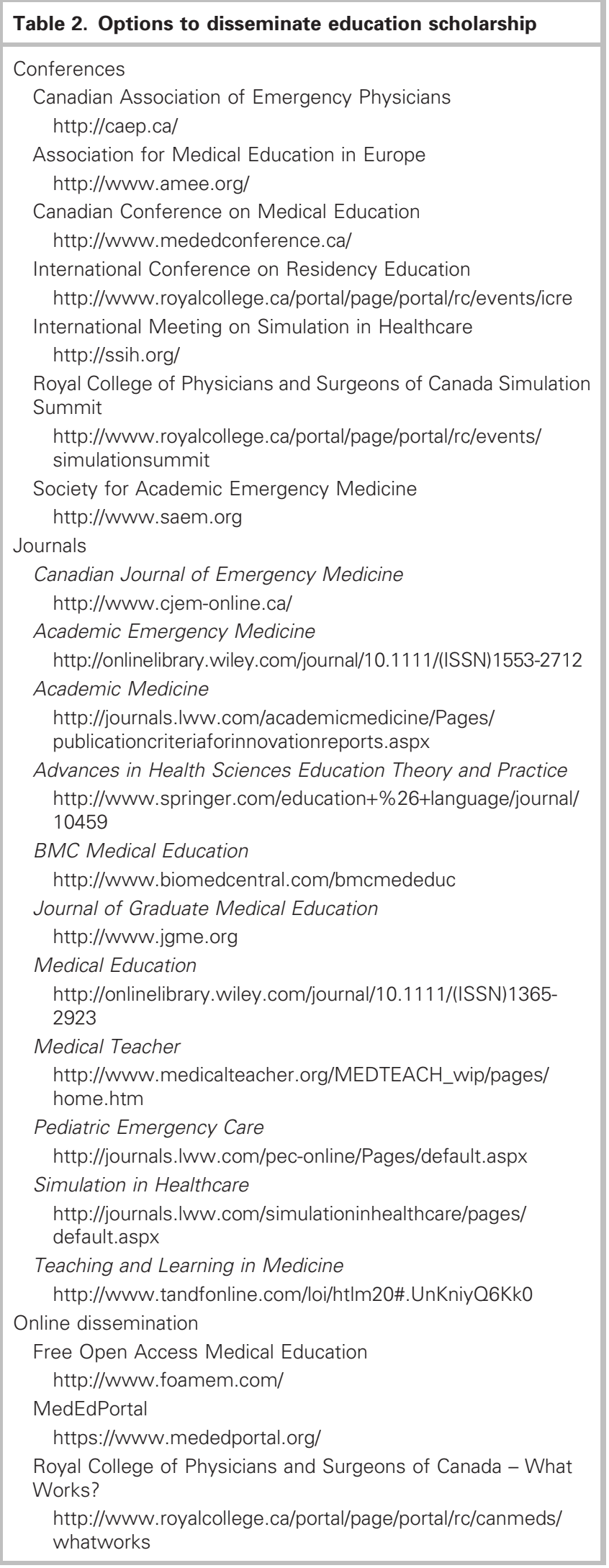


should be represented on the awards decision committee.

- Action Item: The Academic Section should identify existing funding streams and advocate for increased funding for EM scholarship.

- Action Item: The Academic Section should partner with other academic organizations, both EM-specific and general medical, to promote and coordinate education scholarship globally.

2. CAEP should support the dissemination of education scholarship.

- Action Item: The CAEP annual conference should continue to feature education scholarship (both research and innovations) as a prominent track. The submission process should include an alternate abstract form that is more amenable to education innovation, rather than a traditional research abstract.

- Action Item: The Canadian Journal of Emergency Medicine (CJEM) should continue to support education scholarship as a core theme.

- Action Item: The Royal College EM specialty committee and the CCFP-EM program directors committee should disseminate education scholarship across training programs.

- Action Item: The Academic Section should explore the development of an on-line portal to share education scholarship.

\section{CONCLUSION}

Education scholarship can improve the learning process for EM trainees and potentially improve their clinical practice and the outcome of their patients. Successful scholarship requires a systematic approach that includes searching the (grey) literature to build on theories, principles, and best practices; prioritizing opportunities and mobilizing resources; adopting frameworks to guide the development of an innovation and focus the scholarship; integrating a component of program evaluation to determine the outcome of the innovation; and using traditional and emerging avenues to disseminate and archive findings so that other scholars can review and build on the work. The Academic Section of the CAEP adopted a series of recommendations during the 2013 consensus conference that support scholars in producing EM education scholarship.

Competing interests: None declared.

\section{REFERENCES}

1. LaMantia J, Deiorio NM, Yarris LM. Executive summary: education research in emergency medicine-opportunities, challenges, and strategies for success. Acad Emerg Med 2012; 19:1319-22, doi:10.1111/acem.12027.

2. Frank JR. Health profession education research. In: Harvey BJ, Lang ES, Frank JF, editors. The research guide: a primer for residents, other health care trainees, and practitioners. Ottawa: The Royal College of Physicians and Surgeons of Canada; 2011. p. 103-9.

3. Sherbino J, van Melle E, Bandiera G, et al. Education scholarship in emergency medicine part 1: innovating and improving teaching and learning. CFEM 2014;16:00-00.

4. Bandiera G, LeBlanc C, Regehr G, et al. Education scholarship in emergency medicine part 2: supporting and developing scholars. CFEM 2014;16:00-00.

5. Boyer E. Scholarship reconsidered: priorities of the professoriate. Princeton (NJ): The Carnegie Foundation for the Advancement of Teaching; 1990.

6. Fincher RM, Work JA. Perspectives on the scholarship of teaching. Med Educ 2006;40:293-5, doi:10.1111/j.1365-2929. 2006.02404.x.

7. Lamantia J, Kuhn GJ, Searle NS. The CORD Academy for scholarship in education in emergency medicine. Acad Emerg Med 2010;17 Suppl 2:S13-5, doi:10.1111/j.1553-2712.2010. 00895.x.

8. Sherbino J, Snell L, Dath D, et al. A national clinicianeducator program: a model of an effective community of practice. Med Educ Online 2010;15, doi:10.3402/meo.v15i0. $\underline{5356 .}$

9. Tekian A, Roberts T, Batty HP, et al. Preparing leaders in health professions education. Med Teach 2014;36:269-71, doi: $10.3109 / 0142159 X .2013 .849332$.

10. van Melle E, Curran V, Goldszmidt M, et al. Toward a common understanding: advancing education scholarship for clinical faculty in Canadian medical schools. A position paper. Ottawa: Canadian Association for Medical Education; 2012.

11. Kern DE, Thomas PA, Howard DM, et al. Curriculum development for medical education: a six-step approach. Baltimore: John Hopkins University Press; 2009.

12. Sherbino J, Frank JR, editors. Educational design: a CanMEDS guide for the health professions. Ottawa: The Royal College of Physicians \& Surgeons; 2011.

13. Cook DA. Twelve tips for evaluating educational programs. Med Teach 2010;32:296-301.

14. Kirkpatrick DL. Evaluating training programs: the four levels. San Francisco (CA): Berrett-Koehler; 1994.

15. Frye AW, Hemmer PA. Program evaluation models and related theories: AMEE guide no. 67. Med Teach 2012;34: e288-99, doi:10.3109/0142159X.2012.668637. 
16. Haji F, Morin MP, Parker K. Rethinking programme evaluation in health professions education: beyond 'did it work?' Med Educ 2013;47:342-51, doi:10.1111/medu.12091.

17. Cook DA, West CP. Perspective: reconsidering the focus on "outcomes research" in medical education: a cautionary note. Acad Med 2013;88:162-7, doi:10.1097/ACM.0b013e31827c3d78.
18. Sherbino J. Brief educational reports: a new manuscript category. CFEM 2012;14:325.

19. Gordon JA. Reflections on the consensus process: a leadership role for emergency medicine in educational scholarship and practice across health care. Acad Emerg Med 2012;19: 1333-5, doi:10.1111/acem.12020. 